\title{
Lysis of Gram-positive and Gram-negative Bacteria by Antibacterial Monolith Formed in Microfluidic Biochips for Sample Preparation
}

\author{
Mohamed Aly Saad Aly ${ }^{a}$, Mario Gauthier ${ }^{b}$, and John Yeow ${ }^{* a}$
}

\begin{abstract}
Bacterial cell lysis is demonstrated using polymeric microfluidic biochips operating via a hybrid mechanical shearing/contact-killing mechanism. These biochips are fabricated from a cross-linked poly(methyl methacrylate) (X-PMMA) substrate by well-controlled, high-throughput laser micromachining. The unreacted double bonds at the surface of X-PMMA provide covalent bonding for the monolith, thus contributing to the mechanical stability of the biochip and eliminating the need for surface treatment. The lysis efficiency of these biochips was tested for gram-positive (Enterococcus saccharolyticus and Bacillus subtilis) and gram-negative bacteria (Escherichia coli and Pseudomonas fluorescens), and confirmed by off-chip PCR without further purification. The influence of the flow-rate when pumping the bacterial suspension through the monolith, and of the hydrophobic-hydrophilic balance on the cell lysis efficiency was investigated at a cell concentration of $10^{5} \mathrm{CFU} / \mathrm{ml}$. The lysis efficiency of the biochips was better than for off-chip chemical, mechanical, and thermal lysis techniques. The biochip also acts as a filter that isolates cell debris and allows PCR-amplifiable DNA to pass through. As expected, the system performs more efficient lysis for gram-negative than for gram-positive bacteria. The biochip does not require chemical/enzymatic reagents, power consumption, or complicated design and fabrication processes, which makes it an attractive on-chip lysis device that can be used in sample preparation for bio-genetics and point-of-care diagnostics. The biochips were reused for 20 lysis cycles without significant performance degradation or carryover when they were back-flushed between cycles. The biochips efficiently lysed both gram-positive and gram-negative bacteria in about $35 \mathrm{~min}$ per lysis and monolith regeneration cycle.
\end{abstract}

\section{Introduction}

Cell lysis refers to a process in which the cells are broken down by disrupting their membrane and results in the liberation of their cytoplasmic content, namely the DNA, RNA, and proteins essential for molecular genetic analysis and pointof-care diagnostics. Cell lysis, as a primary step in sample preparation, has been achieved through fundamentally different techniques including electrical, thermal, mechanical and chemical methods. Developments in lab-on-a-chip (LOC) techniques have opened up various possibilities to scale down bio-genetics and molecular diagnostic machines into miniaturized devices with numerous advantages such as higher sensitivity and accuracy, and a reduction in the reaction volumes, which in turn minimizes the cost of the reagents and the amount of waste generated.

Electrical cell lysis can be achieved by exposing the cells to a high-intensity pulsed electric field $(\mathrm{PEF})^{1}$ that destabilizes and disintegrates the membranes, by producing nanopores leading to their dielectric breakdown. ${ }^{2}$ The lysis efficiency and time both depend on the electric field strength.

a Department of Systems Design Engineering, University of Waterloo, 200 University Ave West, Waterloo, Ontario, Canada N2L 3G1. E-mail: jyeow@uwaterloo.ca; Fax: +1 519 746-4791; Tel: +1 519 888-4567 Ext. 32152

${ }^{b}$ Department of Chemistry, University of Waterloo

The final publication is available at Springer via http://dx.doi.org/10.1007/s00216-014-8028-9
Electrical cell lysis is reagent free, faster and less expensive than chemical treatment; thus it is widely integrated in microelectromechanical system (MEMS) devices. Unfortunately it requires a high power consumption, which is an unfavorable parameter within miniaturized systems. Electrical cell lysis also often demands complicated designs to accommodate the electrodes, which results in difficult fabrication.

Thermal cell lysis is accomplished by thermal shock consisting of freezing and thawing cycles, or otherwise by heating a cell suspension, ${ }^{3}$ This causes the proteins within the cell membrane to be denatured, which leads to irreparable damage and release of the intracellular components. As an alternative to chemical or enzymatic lysis, thermal cell lysis is useful to avoid contamination in downstream processes. Precise control of the temperature to avoid the denaturation of DNA is a significant challenge in thermal cell lysis. ${ }^{4}$ The high power requirements for heating also make thermal cell lysis undesirable for portable systems.

In chemical lysis, lysing agents can be used to target the cells either through continuous flow in microfluidic channels 5 or by incubation in micro-chambers ${ }^{5}$ or by incubation in micro-chambers. ${ }^{6}$ Buffers such as ammonium chloride, known as Red Blood Cell Buffer, ${ }^{7}$ detergents (disrupting the cell membranes by solubilizing the membrane proteins and lipids, thus creating pores) including Triton X-100 ${ }^{8}$ and sodium dodecyl sulfate (SDS), ${ }^{9}$ chaotropic agents like guanidinium thiocyanate (GTC), ${ }^{9}$ ethanol and magnesium chlo- 
ride (interfering with intermolecular forces in proteins) and enzymes such as lysozyme, ${ }^{10,11}$ lysostaphin and proteinase$\mathrm{k} 11$ (digesting the peptidoglycans in the cell walls, ultimately compromising their integrity) are the most common chemical agents used. Possible interference of the chemical and enzymatic agents used with the subsequent analysis processes is the major downside of chemical lysis.

Mechanical cell lysis is conceptually the simplest method to achieve lysis, as it uses mechanical forces to disintegrate the membrane. There are numerous techniques to disrupt the cell membrane through physical contact between the cells and lysing objects. One method is to force the cells through narrow gaps or pores with sharp edges, that are smaller than the cells, ${ }^{12}$ thereby shearing the cell membrane and rupturing it to release its intracellular content. Burke et al. ${ }^{13}$ thus formed a narrow porous polymeric monolith (PPM) within a poly(dimethylsiloxane) (PDMS) microfluidic channel and used it to lyse white blood cells (B lymphocytes), by shearing the cell membrane through the small pores of the monolith. Mahalanabis et al. ${ }^{14}$ also developed a microfluidic chip to lyse bacterial species and extract genomic DNA by mechanical shearing through a PPM column within a microfluidic channel, but with the assistance of chemical reagents. Blockage generally remains a drawback in such minute flow-through devices.

Antimicrobial polymers are materials possessing antimicrobial properties, i.e. the ability to inhibit the growth and eventually kill microorganisms such as bacteria and fungi. Research is ongoing to engineer these polymers so as to imitate natural host defense peptides (HDPs), used by the immune system in living organisms to kill bacteria. An emerging class of antimicrobial polymers, termed 'synthetic mimics of antimicrobial peptides' (SMAMPs), ${ }^{15}$ was synthesized to mimic the main features of HDPs: cationic charge and amphiphilic character, which facilitate the permeation and disintegration of bacterial membranes. An antimicrobial surface is a form of antimicrobial polymer killing cells by contact. Tiller et al. ${ }^{16}$ introduced in 2001 surfaces that killed bacteria upon contact, and termed it 'contact-killing'. Wan et al. ${ }^{17}$ further described an integrated microchip system allowing cell lysis and PCR within the same reaction chamber. They used gold nanoparticles modified with an antibacterial polymer on their surface for cell lysis. The biocidal activity of the antibacterial polymer and the high surface area to volume ratio (SAVR) of the gold nanoparticles led to enhanced cell lysis. Unfortunately, the modified gold nanoparticles also caused PCR inhibition; this was attributed to interactions between the nanoparticles and DNA polymerase.

We recently described a new cell lysis method using antibacterial PPM columns fabricated within a $20 \%$ cross-linked poly(methyl methacrylate) (X-PMMA) microfluidic channel, that effectively lysed Escherichia coli (E. coli) and Bacil- lus subtilis (B. subtilis) without requiring chemical/enzymatic reagents, power consumption, or complicated design and fabrication processes, making it an attractive on-chip cell lysis technique. ${ }^{18}$ We now expand the scope of this work considerably to enhance the cell lysis efficiency, by tuning the hydrophobic-hydrophilic balnce of the PPM columns. The optimal flow rate, at which the bacterial cell walls are sufficiently mechanically sheared through the porous PPM column to disrupt the cell membrane by physical contact with the antibacterial polymeric biocide covering the pore surface, was also determined. The usefulness of this new technique was also further confirmed in terms of reusability of the monolithic columns, by demonstrating that the PPM columns suffer from no significant performance loss when used in successive lysis cycles. The biochips efficiently lysed both gram-positive and gram-negative bacteria, producing cell lysates containing DNA that could be amplified by off-chip PCR without the need for purification, which proves that the monoliths do not leach PCR inhibitors making them unsuitable for sample preparation. In this investigation, we also added Pseudomonas fluorescens (p. fluorescens) and Enterococcus saccharolyticus (E. saccharolyticus), to further expand lysis testing of the antibacterial columns with gram-negative and gram-positive bacteria, respectively.

\section{Experimental}

\section{Materials}

Methyl methacrylate (MMA, $99 \%$ ), butyl methacrylate (BuMA, $99 \%$ ), ethylene glycol dimethacrylate (EGDMA, $98 \%$ ), and 1,6-hexanediol dimethacrylate (1,6-HDDMA, $\geq 90 \%$ ) were all purchased from Sigma-Aldrich (Oakville, ON Canada), and passed through alumina columns to remove inhibitors. 1-Dodecanol (98\%, reagent grade), cyclohexanol (99\% Reagent Plus), 2,2-dimethoxy-2-phenylacetophenone (DMPAP, $99 \%)$, methanol ( $\geq 99.9 \%$ Chromasolv), fumed silica (powder, 0.2-0.3 $\mu \mathrm{m}$ average particle size), phosphoric acid $(85 \%)$, ethylenediaminetetraacetic acid (EDTA, BioUltra, anhydrous, $\geq 99 \%$ ), and lysozyme (lyophilized powder, protein $\geq 90 \%$ ) were also purchased from Sigma-Aldrich but were used without further purification. iTaq polymerase, 10X PCR buffer, and magnesium chloride were obtained from BioRad.(Montereal, QC Canada) Primers and dNTP mix (dATP, dCTP, dGTP and dTTP) were obtained from Sigma-Aldrich. Ethidium bromide (UltraPure $10 \mathrm{mg} / \mathrm{mL}, \mathrm{EtBr}$ ) and UltraPur Dithiothreitol (DTT, Cleland's reagent) were purchased from Life Technologies Inc. (Burlington, ON Canada). A 1k bp DNA ladder was purchased from BioLabs (Ipswich, MA). 
Table 1 Compositions of the eleven monolith solutions (in wt. \%). ${ }^{\mathrm{a}}$

\begin{tabular}{lllll}
\hline & & Monomers & Cross-linkers \\
\hline Monolith & BuMA & Boc-AEMA $^{\mathrm{b}}$ & EGDMA & 1,6-HDDMA \\
\hline 1 & 1.3 & 15.6 & 9.1 & - \\
2 & 1.3 & 15.6 & 8.1 & 1.0 \\
3 & 1.3 & 15.6 & 7.1 & 2.0 \\
4 & 1.3 & 15.6 & 6.1 & 3.0 \\
5 & 1.3 & 15.6 & 5.1 & 4.0 \\
6 & 1.3 & 15.6 & 4.1 & 5.0 \\
7 & 1.3 & 15.6 & 3.6 & 5.5 \\
8 & 1.3 & 15.6 & 3.1 & 6.0 \\
9 & 1.0 & 15.9 & 3.1 & 6.0 \\
10 & 0.5 & 16.4 & 3.1 & 6.0 \\
11 & - & 16.9 & 3.1 & 6.0 \\
\hline
\end{tabular}

a All the reactions also included $21.5 \%$ cyclohexanol and $52.3 \%$ 1-dodecanol as porogens, and $0.2 \%$ DMPAP as photoinitiator.

${ }^{b}$ aMonomer synthesis as described by Aly Saad Aly et al. ${ }^{18}$.

\section{Microchip fabrication}

The microfluidic channels were laser-micromachined within $20 \%$ X-PMMA substrates with a $10.6 \mu \mathrm{m} \mathrm{CO}_{2}$ laser engraving system (Universal Laser Systems, VLS2.30). The synthesis procedure for X-PMMA was described by Aly Saad Aly et al. ${ }^{18}$ The channels were $2.5 \mathrm{~cm}$ in length, $500 \mu \mathrm{m}$ wide, and $250 \mu \mathrm{m}$ deep. To obtain an enclosed channel another piece of the X-PMMA substrate, with two holes drilled for the inlet and outlet, was chemically bonded with the substrate hosting the microchannel by applying a thin layer of BuMA between the two X-PMMA layers, and placing the top and bottom substrates in a hot press under pressure $\left(130^{\circ} \mathrm{C}, 10^{3} \mathrm{psi}\right)$ for 30 min (Heated Press 4386, Carver, Wabash, IN). Two 30G syringe needles were trimmed and placed over the inlet and outlet holes, and set with epoxy glue mixed with fine fumed silica powder to achieve a hard and stable adhesive.

\section{Monolith formation and antibacterial activation}

Mixtures with compositions as summarized in Table 1 were sonicated for $30 \mathrm{~min}$ to help dissolve the crystalline BocAEMA, stirred for 30 min under $\mathrm{N}_{2}$ flow, and then introduced into the microchannel. Polymerization was triggered by irradiation of the substrate for 15 min with a $365 \mathrm{~nm}$ UV source in a cabinet containing a UV lamp $\left(200 \mathrm{~mJ} / \mathrm{cm}^{2}\right.$ intensity, ENF-260C, Spectronics Corp. Westbury, NY). The substrate was then turned over and irradiated with the UV source on the other side for 15 min longer. Using a Pico plus syringe pump (Harvard apparatus, Holliston, MA), the microchannel was then flushed with ethanol to remove the porogens and any unreacted monomer. Activation of the antibacterial monolithic column was achieved through deprotection of the Boc-AEMA units by flowing $250 \mu \mathrm{L}$ of phosphoric acid through the mono- lith, before flushing with $250 \mu \mathrm{L}$ of ethanol and $250 \mu \mathrm{L}$ of deionized (DI) water to remove acid residues. ${ }^{18}$ The deprotection process was validated by acquiring Fourier transform infrared spectroscopy (FT-IR) spectra for the porous column material. ${ }^{18}$

\section{Bacterial culture}

E. coli DH5 $\alpha$ and P. fluorescens (ATCC 13525) were served as gram-negative test bacterial strains, while B. subtilis 168 and E. saccharolyticus (ATCC 43076) were used as gram-positive strains. E. coli DH5 $\alpha$ and B. subtilis 168 were donated by Dr. Michael Palmer (Chemistry Department, University of Waterloo). E. saccharolyticus and P. fluorescens were purchased from American Type Culture Collection (ATCC, Manassas, VA, catalog numbers ATCC 43076 and ATCC 13525, respectively). Dgetails about bacterial culture and the growth conditions are provided in the Supporting Information.

\section{Bacterial cell lysis}

Samples of $2.5 \mathrm{~mL}$ each of the four bacterial cultures at concentration of $1.510^{5}, 210^{5}, 1.710^{5}$ and $1.910^{5}$ for for E. coli, B. subtilis, P. fluorescens and E. saccharolyticus, respectively, were pelleted at 13k RPM for 3 min, washed twice with DI water, and then re-suspended in phosphate-buffered saline (PBS).

On-chip cell lysis. A $110 \mu \mathrm{L}$ aliquot of the bacterial suspensions was pumped at a flow rate of $1.5 \mu \mathrm{L} / \mathrm{min}$ through each of the monoliths prepared as described in Table 1, after deprotection, and the cell lysate was collected at the biochip outlet to investigate the influence of the hydrophobichydrophilic balance on the cell lysis efficiency of the antibacterial monoliths. The bacterial suspension was also pumped through monolith (11) before and after deprotection, at flow rates starting at $0.1 \mu \mathrm{L} / \mathrm{min}$, and then increased in $0.4 \mu \mathrm{L} / \mathrm{min}$ increments after pumping $50 \mu \mathrm{L}$ at each flow rate, to examine the influence of the flow rate on the cell lysis efficiency of the biochips.

To invistigate the reusability of the biochips, a biochip was reused 35 times and the cell lysis efficiency was evaluated for each cycle. The E. coli bacteria suspended in PBS used in this test were passed through the antibacterial monolith with the optimal composition and at the optimal flow rate. Two different column washing procedures were compared for their influence on the cell lysis efficiency. In the first procedure (PBS wash), the monolith was back-flushed after each run with 20 $\mu \mathrm{L}$ of PBS buffer; after ten runs it was also washed with $25 \mathrm{~L}$ of phosphoric acid and then with $20 \mu \mathrm{L}$ of PBS. In the second procedure (Acid wash), the monolith was back-flushed after each use with $25 \mu \mathrm{L}$ of phosphoric acid and then with $20 \mathrm{~L}$ of PBS buffer. To investigate possible of DNA carryover, the 
PBS recovered from the microfluidic channel in the back-flush cycle was mixed with EtBr and any changes in fluorescence intensity were recorded.

Off-chip cell lysis. Aliquots of the bacterial suspensions (300 $\mu \mathrm{L}$ ) were pipetted into three centrifuge tubes. For thermal cell lysis, one tube was immersed in a $90{ }^{\circ} \mathrm{C}$ water bath for three min and in a dry ice/acetone bath for three more min to create a thermal shock. This freeze-thaw cycle was repeated three times. More details about the off-chip mechanical and chemical cell lysis protocols are provided in the Supporting Information.

\section{Cell Lysis efficiency}

The bacterial cell lysates collected at the outlet of the biochips described in Table 1 were analyzed to study the influence of the hydrophobic-hydrophilic balance and the flow rate on the cell lysis efficiency of the monoliths by the methods described below.

DNA detection by fluorometry. The ethidium bromide (EtBr) intercalation assay was used as an indicator of the presence of DNA in the cell lysate. A $0.02 \mathrm{~mL}$ aliquot of the bacterial cell lysate was added to a spectrofluorometer cuvette containing $0.380 \mathrm{~mL}$ of DI water and $0.03 \mathrm{~mL}$ of $\mathrm{EtBr}$ from a stock solution with a concentration of $0.4 \mathrm{mg} / \mathrm{L}$, and the fluorescence intensity of $\mathrm{EtBr}$ was measured at a wavelength of $595 \mathrm{~nm}$ measured on a Quanta-Master 4 spectrofluorometer (Photon Technology International, London, ON Canada).

DNA concentration by UV-Vis spectrophotometry. A 4 $\mu \mathrm{L}$ aliquot of PBS buffer was pipetted onto the end of a fiber optic cable (receiving fiber) of a UV-Vis Spectrophotometer NanoDrop 2000c (Thermo Scientific, Mississauga, ON Canada)to serve as blank (reference). A second fiber optic cable (source fiber) was then brought into contact with the liquid sample, causing the liquid to bridge the gap between the fiber optic ends. Then a $4 \mu \mathrm{L}$ sample of the E. coli DH5 $\alpha$, B. subtilis 168, P. fluorescens (ATCC 13525), or E. saccharolyticus (ATCC 43076) bacterial cell lysate was separately pipetted onto the receiving fiber, to measure the DNA concentration in the lysate after flowing the cell suspension through both the protected and deprotected columns.

PCR reagents and experimental setup. The PCR reaction was performed in a T100 Thermal Cycler (Bio-Rad, Montreal, QC Canada) in a $25 \mu \mathrm{L}$ volume consisting of $300 \mathrm{nM}$ of forward primer, $300 \mathrm{nM}$ of reverse primer, $200 \mu \mathrm{M}$ of dNTPs, $3.5 \mathrm{mM}$ of magnesium chloride, $0.625 \mathrm{U}$ of iTaq polymerase, $2.5 \mu \mathrm{L}$ of 10X PCR buffer, and $200 \mathrm{ng}$ of DNA present in the crude cell lysate collected at the outlet of the biochip. More details about the bacterial cultures and the growth conditions, the primers structure (Table S1), and the PCR cycles are provided as Supporting Information.

Gel electrophoresis. A Bio-Rad gel electrophoresis apparatus served to analyze the PCR products on $1.2 \%$ agarose gel, using a DC voltage of $85 \mathrm{~V}$ and a running time of $30 \mathrm{~min}$. The gel was subsequently removed from the chamber and imaged with a Bio-Rad Doc XR imaging system.

\section{Results and discussion}

\section{Influence of the hydrophobic-hydrophilic balance}

It was previously determined that the hydrophobichydrophilic balance is a critical parameter controlling the activity of antibacterial polymers (SMAMPs). ${ }^{19}$ Thus we investigated the effect of varying the amphipathic nature of the antibacterial monoliths on their cell lysis efficiency, by changing the proportions of the hydrophobic (BuMA) and the amine-containing hydrophilic (Boc-AEMA) monomers, as well as the cross-linking hydrophobic (1,6-HDDMA) and hydrophilic (EGDMA) monomers, as outlined in Table 1).

The ethidium bromide (EtBr) intercalation assay sevred to detect DNA in the cell lysate, as evidence for cell lysis. When ethidium bromide (EtBr) is exposed to UV light at $285 \mathrm{~nm}$ it fluoresces with an orange color at $595 \mathrm{~nm}$, which intensifies considerably after its intercalation in DNA. The fluorescence intensity for $\mathrm{EtBr}$ before and after intercalation in the DNA present in the cell lysate collected at the outlet of the porous antibacterial monoliths (1-11) was quantified on a spectrofluorometer to obtain Fig. 1.

As can be seen from Fig. 1, the fluorescence intensity for the tested monoliths can be divided into three groups: Groups I (columns 1 through 5), II (columns 6 through 8), and III (columns 9 through 11). In Group I, the fluorescence intensity of EtBr gradually increases as the content in the hydrophobic (1,6-HDDMA) and hydrophilic (EGDMA) crosslinking monomers increase and decrease within that series, respectively. This reflects increasing DNA concentrations in the crude lysates collected at the outlet of the microfluidic channels hosting the monoliths, and therefore enhanced lysis as the columns become increasingly hydrophobic. In Group II, the fluorescence intensity of EtBr is relatively insensitive to further variations in hydrophobic and hydrophilic crosslinking monomers (columns 6-8). This saturation shows that further increasing the hydrophobicity of the monoliths does not lead to improved lysis ability for the bacterial species tested in this study. In Group III, the fluorescence intensity of EtBr again increases as the contents of the hydrophobic (BuMA) and hydrophilic, positively charged (AEMA) noncross-linking monomers decrease and the increase, respectively, in the last monoliths. This increase could be ibuted to further changes in the hydrophobic-hydrophilic balance, but 
- B. subtilius • E. saccharolyticus - E. coli - P. fluorescens

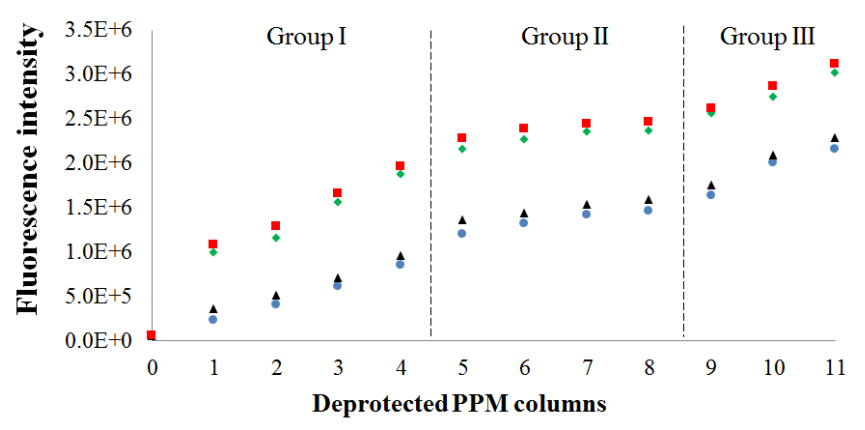

Fig. 1 Florescence intensity of EtBr after intercalating into the DNA released from bacterial cells flowing through the microfluidic channels hosting the different PPM columns.

(on the basis of the trends described above) it is more likely due to increased charge density in the monolith as a result of the higher concentration of the positively charged amine monomer (AEMA).

To validate the cell lysis results obtained by the EtBr assay and to directly quantify the lysis efficiency of the different columns, the DNA concentration in the cell lysates collected at the exit of the microfluidic channels was determined by UV-Vis spectrophotometry as shown in Fig. 2. It can be seen that the DNA concentration in the different cell lysates also matches the three regions identified in Fig. 1. This further confirms that column (11) had the highest antibacterial activity among the different monolith columns investigated; thus it was used for the subsequent experiments. Fig. 1 and Fig. 2 both show that the biochips display a comparable lysis efficiency for P. fluorescens and E. coli ( the two gram-negative bacteria), as well as for E. saccharolyticus and B. subtilis (the gram-positive bacteria). However it is clear that the lysis efficiency is significantly higher for the gram-negative than for the gram-positive bacteria within the monolith composition range investigated. This is reasonable since gram-positive bacteria have a thicker cell membrane than gram-negative bacteria, which makes them harder to lyse.

\section{Influence of flow rate}

The bacterial cell wall/membrane is mechanically sheared by flowing through the porous medium of the monolith, but it is also damaged and disintegrated by physical contact with the antibacterial polymeric biocide covering the porous surface. Both effects lead to leakage of the intracellular content. Burke et al. ${ }^{13}$ thus reported that the flow rate was a critical factor in the mechanical shearing of B lymphocyte cells in porous monolith columns. They demonstrated that B lymphocyte cells could only be mechanically lysed when the cell sus-

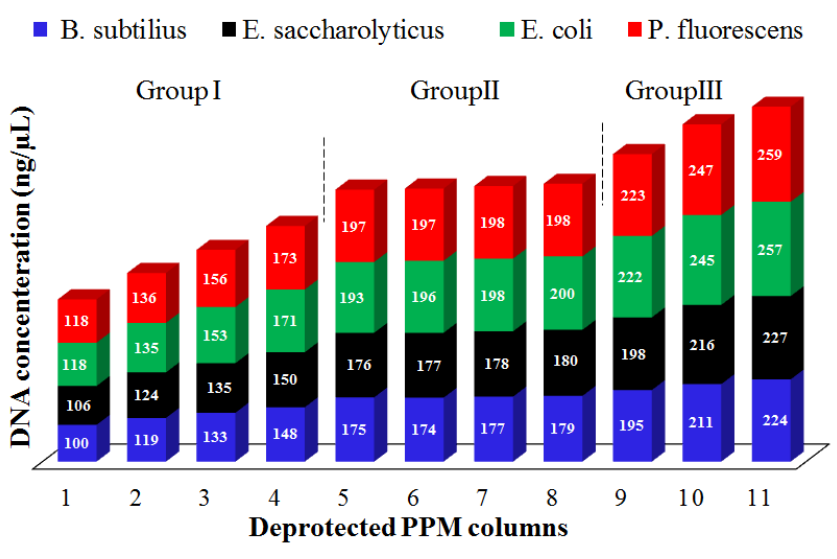

Fig. 2 Absolute concentration of DNA present in the crude cell lysate collected at the outlet of the different monoliths.

pension was pumped at a flow rate of at least $5 \mu \mathrm{L} / \mathrm{min}$ for the specific system they used. In the current study, we investigated the influence of the flow rate on both mechanical shearing and contact killing for bacterial cell lysis. Control samples were prepared for the ethidium bromide intercalation assay containing $0.02 \mathrm{~mL}$ of bacterial cell suspensions that were not flown through the monolith, $0.380 \mathrm{~mL}$ of DI water, and $0.03 \mathrm{~mL}$ of $\mathrm{EtBr}$ from a stock solution with a concentration of $0.4 \mathrm{mg} / \mathrm{L}$.

Protected PPM Column. Before removing the Boc protecting group from the Boc-AEMA monomer, the concentration of DNA in the cell lysates collected from column (11) varied with the flow rate according to four different regimes as shown in Fig. 3. At flow rates below $1.2 \mu \mathrm{L} / \mathrm{min}$ (Regime i) the fluorescence intensity for EtBr was similar to the control sample, indicating that no significant lysis took place. This implies that the cells cannot be mechanically lysed through the porous medium of the monolith unless the flow rate exceeds a certain threshold value, in agreement with the findings of Burke et al. At flow rates between 1.2 and $4.8 \mu \mathrm{L} / \mathrm{min}$ (Regime ii) the fluorescence intensity of EtBr (and the DNA concentration) increased rapidly, as shown in Fig. 3 (and Fig. $\mathrm{S} 1$, in the Supporting Information). However at flow rates between 5.2 and $7.6 \mu \mathrm{L} / \mathrm{min}$ (Regime iii) the fluorescence intensity of EtBr and the DNA concentration gradually leveled off (decreasing slope). In these two regimes, as the flow rate increases, the bacterial cells are forced faster through the porous medium of the monolith, which results in more mechanical lysis of the cells. Finally, at flow rates between 6.7 and 10 $\mu \mathrm{L} / \mathrm{min}$ (Regime iv) the fluorescence intensity of EtBr and the DNA concentration saturated which shows that there was no influence of the flow rate on cell lysis efficiency beyond $6.7 \mu \mathrm{L} / \mathrm{min}$. The influence of the flow rate on cell lysis was therefore highest in Regime ii, less significant in Regime iii, and insignificant in Regime iv. The results also reveal that 


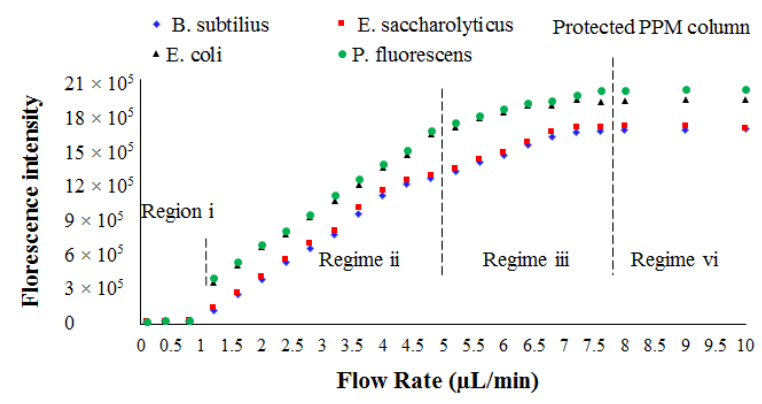

Fig. 3 Florescence intensity of EtBr after intercalating into the DNA released from bacterial cells pumped through the protected PPM column (11) at different flow rates.

the lysis efficiency was higher for gram-negative than grampositive bacteria within the flow rate range investigated. This was again expected, as gram-positive bacteria are harder to lyse due to their thicker cell membranes.

Deprotected (antibacterial) PPM column. After deprotecting the amine group of the Boc-AEMA monomer, the concentration of DNA in the cell lysates was found to vary with the flow rate in five different regimes, as shown in Fig. 4. At flow rates below $1.2 \mu \mathrm{L} / \mathrm{min}$ (Regime i) the DNA concentration are similar to the control samples, indicating that no lysis happened. This further confirms the results gathered for the protected monolith.

At flow rates between 1.2 and $3.6 \mu \mathrm{L} / \mathrm{min}$ (Regime ii), the DNA concentration increased rapidly.The DNA concentration (and The fluorescence intensity of EtBr) at a flow rate of $1.2 \mu \mathrm{L} / \mathrm{min}$, shown in Fig. 4 and Fig. S2 (Supporting Information), are 13 times higher and more than twice higher, respectively, than the values obtained before deprotection (Fig. 3 and S1). This confirms that additional lysis took place after deprotection due to the antibacterial nature of the monolithic surface. At flow rates between 4 and $6 \mu \mathrm{L} / \mathrm{min}$ (Regime iii), the DNA concentration (and fluorescence intensity of EtBr)saturated. This contrasts with the trend observed before deprotection within the same flow rate range, since the fluorescence intensity of EtBr and the DNA concentration continued to increase. At flow rates between 6.4 and $7.6 \mu \mathrm{L} / \mathrm{min}$ (Regime iv) the fluorescence intensity of EtBr and the DNA concentration both decreased rapidly, while the fluorescence intensity of EtBr and DNA concentration continued to increase over the same flow rate range for the columns in the protected state. At flow rates between 8 and $10 \mu \mathrm{L} / \mathrm{min}$ (Regime v) the fluorescence intensity of EtBr and the DNA concentration levelled off again.

These results show that when the flow rate exceeds a critical value the bacterial cells spend insufficient time in contact with the antibacterial surface of the monolith, which leads to less efficient contact-killing lysis. Mechanical shearing lysis is still taking place $(4-7.6 \mu \mathrm{L} / \mathrm{min})$ however, until the flow rate reaches a value $(8 \mu \mathrm{L} / \mathrm{min})$ where further increasing the flow rate has no effect on both lysis mechanisms. The highest overall cell lysis efficiency (highest overall DNA concentration and fluorescence intensity) is therefore achieved at flow rates between 4 and $6 \mu \mathrm{L} / \mathrm{min}$, as a result of a combination of mechanical shearing and contact-killing mechanisms.

\section{Reusability of the biochip}

The change in EtBr fluorescence intensity due to its intercalation in the DNA present in the cell lysate is compared in Fig. 5 after each injection and flushing cycle for the two different washing protocols examined. It can be seen that for the PBS washing protocol the antibacterial efficiency decreases slightly over 10 cycles, but washing of the monolith with phosphoric acid then restores the activity to some extent. This could be due to gradual deprotonation of the amine caused by the sequential PBS washes, which is being protonated again by the phosphoric acid wash. The decrease in activity observed for the Acid wash protocol is much more gradual. It is interesting to note that after the twentieth use, the lysis efficiency started degrading dramatically regardless of the washing protocol used. The monolith was completely blocked after 30-35 cycles. Gradual blockage of the pores by cell debris, leading to a decrease in the surface area of the porous monolith column accessible to the cells, may therefore also explain in part the gradual decrease in cell lysis efficiency observed over multiple cycles. Irrespective of the washing protocol used, the performance of the biochip appears acceptable over multiple cycles since the lysis efficiency only decreased by $10 \%$ over 20 cycles. The florescence intensity of EtBr mixed with the PBS recovered from the microfluidic channel in the back-flush cycle showed insignificant DNA carry over, reaching only $0.6 \%$ of the maximum EtBr intensity reported as shown in Table S2 (Supporting Information). It is also worth mentioning that the total cycle time for the biochip was 35 min including both sample lysis and monolith regeneration. 


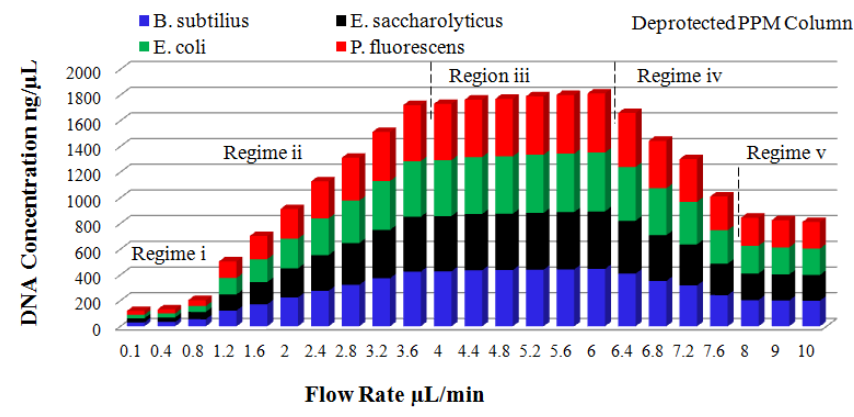

Fig. 4 Concentration of the DNA present in the crude bacterial cell lysate collected at the outlet of the microfluidic channels hosting deprotected PPM column (11) flown at different flow rates.

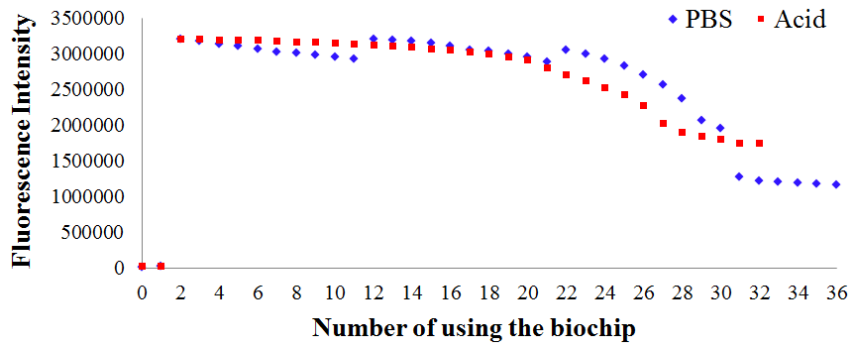

Fig. 5 Fluorescence intensity for EtBr intercalated into the DNA released from bacterial cells flowing through the protected monolith (11) at $4 \mu \mathrm{L} / \mathrm{min}$ over successive runs for the two different washing protocols (PBS and Acid).

\section{Biochip vs. off-chip cell lysis}

A $100 \mu \mathrm{L}$ aliquot of the bacterial suspension (at the same concentration used in the monolith lysis experiments) was lysed by the off-chip cell lysis methods. The efficiency of the different cell lysis techniques, including the biochip method, is compared in Fig. 6. It is clear that the DNA concentration in the cell lysate collected from the biochip was higher than for the off-chip (mechanical, thermal and chemical) methods. This shows that the biochip approach led to more efficient lysis of the bacterial species tested than the traditional off-chip techniques. Furthermore, the biochip lysis method does not require power consumption (apart from the pump operation), chemical/enzymatic reagents, the use of centrifugation, sonication, nor a complicated design and fabrication process. As a result, the on-chip cell lysis technique developed appears well-suited for incorporation in an integrated sample preparation system.

\section{PCR and gel electrophoresis}

The genes in the DNA released by lysing the bacterial cells were amplified by PCR and qualitatively validated by gel elec-

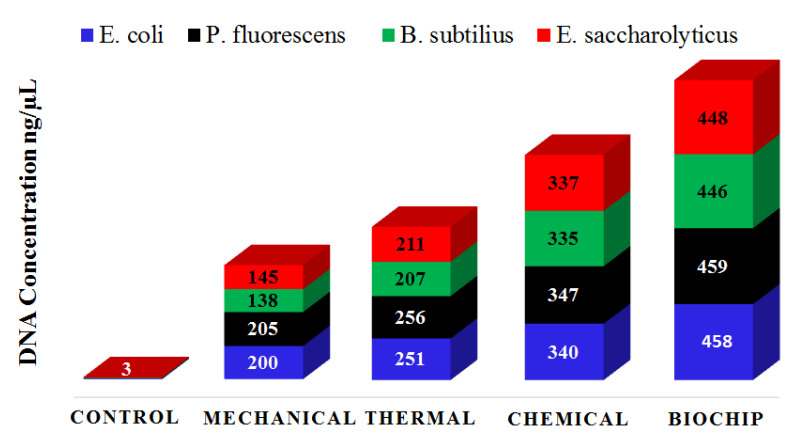

Fig. 6 Concentration of DNA in the crude bacterial cell lysate collected at the outlet of monolith (11) at a flow rate of $4 \mu \mathrm{L} / \mathrm{min}$, and after mechanical, thermal and chemical cell lysis.

trophoresis. The analysis results are shown in Fig. 7 for the PCR products of E. saccharolyticus (column 2), B. subtilis (column 5), P. fluorescens (column 7), and E. coli (column 9) bacterial cells that were not passed through the porous monolith column, and the PCR products of E. saccharolyticus (column 3), B. subtilis (column 4), P. fluorescens (column 6), and E. coli (column 8) bacterial cell lysates collected at the outlet of the deprotected monolith. There are no detectable amounts of DNA at the PCR output for the bacteria samples that were not lysed in the monolithic column, which confirms that the cells had intact membranes before passing through the monolith. In contrast, DNA is clearly detected at the PCR output for the samples that were passed through the deprotected monolith, which shows that the membrane of cells was disintegrated by flowing through the monolith. This is a clear sign for lysis, but also demonstrates that the antibacterial monoliths did not leach any PCR inhibitors. 


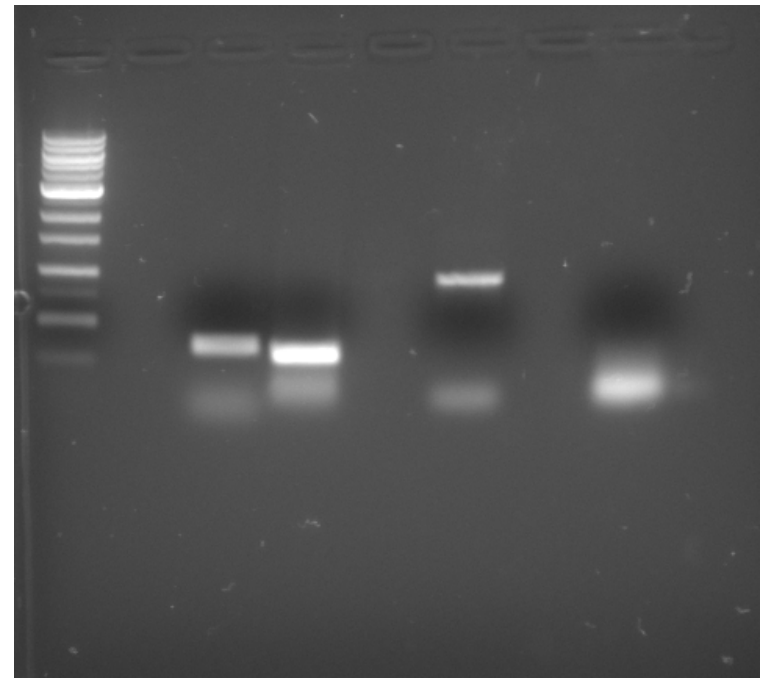

Fig. $7 \mathrm{Gel}$ electrophoresis analysis of PCR output for unlysed (column 2) and lysed (through monolith) (column 3) E. saccharolyticus; unlysed (column 5) and lysed (through monolith) (column 4) B. subtilis; unlysed (column 7) and lysed (through monolith) (column 6) P. fluorescens; and unlysed (column 9) and lysed (through monolith) (column 8) E. coli. Column 1 is for a $1 \mathrm{k}$ bp DNA ladder.

\section{Conclusions}

Microfluidic biochips were fabricated that have the ability to efficiently lyse four species of gram-positive and gramnegative bacteria: E. saccharolyticus (ATCC 43076), B. subtilis 168, E. coli DH5, and P. fluorescens (ATCC 13525). The lysis ability of the biochips was validated with the ethidium bromide intercalation assay, relating the presence of DNA in the cell lysate with an increase in fluorescence intensity for EtBr, and UV-Vis spectrophotometry to directly determine the DNA concentration in the cell lysate. Gel electrophoresis analysis of the PCR products after DNA gene amplification of the cell lysate showed that the monoliths did not leach any material interfering with the PCR process. The performance of the microfluidic biochips developed exceeded that of the traditional off-chip mechanical, thermal, and chemical cell lysis techniques. The influence of the hydrophobic-hydrophilic balance on the lysis efficiency was investigated, and the antibacterial monolith with the highest lysis efficiency was used to determine the influence of the flow rate of the bacterial suspension through the porous monolith. It was also shown that the biochips can be reused for at least twenty times without significant performance degradation or carryover when they are back-flushed between cycles.

\section{Acknowledgements}

We would like to express our gratitude to Grand Challenges Canada and Bigtec Labs for their financial support. We also like to thank Prof. Michael Palmer, Mr. Mohamed Salah, Mr. Eric K. Brefo-Mensah, and Mr. Olivier Nguon from the Chemistry Department at the University of Waterloo, for providing E. coli and B. subtilus bacterial samples, access to their lab facilities and their guidance on some of the biological and chemical concepts.

\section{Supporting information}

Additional figures and information as noted in text. This material is available free of charge via the Internet at http://pubs.acs.org.

\section{References}

1 D. W. Lee and Y.-H. Cho, Sens. Actuat. B-Chem., 2007, 124, $84-89$.

2 D. C. Chang, B. M. Chassy, J. A. Saunders and A. E. Sowers, Guide to Electroporation and Electrofusion, Academic Press, San Diego, 1992.

3 J. Sambrook and D. W. Russel, Molecular Cloning: A Laboratory Manual, Cold Spring Harbor, New York, 2001.

4 C.-Y. Lee, G.-B. Lee, J.-L. Lin, F.-C. Huang and C.-S. Liap, J. Micromech. Microeng., 2004, 15, 1215-12233.

5 D. Irimia, R. G. Tompkins and M. Toner, Anal. Chem., 2004, 76, 6137 6143.

6 M. Cichova, M. Proksova, L. Tothova, H. Santha and V. Mayer, Cent. Eur. J. Biol., 2012, 7, 230-240.

7 P. Sethu, M. Anahtar, L. L. r. Moldawe, R. G. Tompkins and M. Tone, Anal. Chem., 2001, 76, 6247-6253.

8 J. El-Ali, S. Gaudet, A. Gunther, P. K. Sorger and K. F. Jensen, Anal. Chem., 2005, 77, $3629-3636$.

9 E. A. Schilling, A. E. Kamholz and P. Yager, Anal. Chem., 2002, 74, 1798 $-1804$.

10 Y.-B. Kim, J.-H. Park, W.-J. Chang, Y.-M. Koo, E.-K. Kim and J.-H. Kim, Biotechnol. Bioproc. E., 2006, 11, 288 - 292.

11 J. Hall, E. Felnagle, M. Fries, S. Spearing, L. Monaco and A. Steele, Planet. Space Sci., 2006, 54, 1600 - 1611.

12 D. D. Carlo, K.-H. Jeong and L. P. Lee, Lab Chip, 2003, 3, 287-291.

13 J. M. Burke and E. Smela, Biomicrofluidics, 2012, 6, 016506-1-01650610.

14 M. Mahalanabis, H. Al-Muayad, M. D. Kulinski, D. Altman and C. M. Klapperich, Lab Chip, 2009, 9, 2811-2817.

15 K. Lienkamp, A. E. Madkour, A. Musante, C. F. Nelson, K. Nusslein and G. N. Tew, J. Am. Chem. Soc., 2008, 130, 9836-9843.

16 J. C. Tiller, C.-J. Liao, K. Lewis and A. M. Klibanov, J. Am. Chem. Soc., 2001, 98, 5981-5985.

17 W. Wan and J. T. Yeow, Biomed. Microdevices, 2012, 14, 337-346.

18 M. Aly Saad Aly, O. Nguon, M. Gauthier and J. T. Yeow, RSC Adv., 2013, 3, 24177-24184.

19 A. Rao, Arch. Biochem. Biophys., 1999, 361, $127-134$.

\section{Graphical TOC Entry}




\begin{tabular}{|c|c|}
\hline & \begin{tabular}{c} 
UV-Vis \\
\hline Spectrophotometry
\end{tabular} \\
\hline & \begin{tabular}{|c|}
\hline Fluorometry \\
\hline PCR
\end{tabular} \\
\hline & $\begin{array}{c}\text { Gel } \\
\text { Electrophoresis }\end{array}$ \\
\hline
\end{tabular}

